\title{
Comparative Study of Corrosion Performance of HVOF-Sprayed Coatings Produced Using Conventional and Suspension WC-Co Feedstock
}

\author{
R. Ahmed ${ }^{1}(\mathbb{D})$ G. Vourlias $^{2}$ - A. Algoburi ${ }^{1}$ - C. Vogiatzis $^{3}$ - D. Chaliampalias ${ }^{2}$

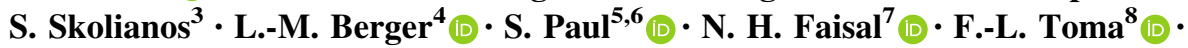 \\ N. M. Al-Anazi ${ }^{9}$ (I) M. F. A. Goosen ${ }^{10}$
}

Submitted: 24 May 2018/in revised form: 26 September 2018/Published online: 30 October 2018 (C) The Author(s) 2018

\begin{abstract}
Corrosion properties of nanostructured coatings deposited by suspension high-velocity oxy-fuel (S-HVOF) via an aqueous suspension of milled WC-Co powder were compared with conventional HVOF-sprayed coatings. Microstructural evaluations of these coatings included $\mathrm{x}$-ray diffraction and scanning electron microscopy equipped with an energy-dispersive x-ray spectroscopy. The corrosion performance of AISI440C stainless steel substrate and the coatings was evaluated in a $3.5 \mathrm{wt} . \% \mathrm{NaCl}$ aqueous solution at $\sim 25^{\circ} \mathrm{C}$. The electrochemical properties of the samples were assessed experimentally,
\end{abstract}

R. Ahmed

R.Ahmed@hw.ac.uk

1 School of Engineering and Physical Sciences, Heriot-Watt University, Edinburgh EH14 4AS, UK

2 Department of Physics, Aristotle University of Thessaloniki, 54124 Thessaloníki, Greece

3 Department of Mechanical Engineering, Aristotle University of Thessaloniki, 54124 Thessaloníki, Greece

4 Fraunhofer IKTS, Fraunhofer Institute for Ceramic Technologies and Systems, Winterbergstrasse 28, 01277 Dresden, Germany

5 Materials Group, TWI, Cambridge CB21 6AL, UK

6 Department of Engineering, University of Leicester, Leicester LE1 7RH, UK

7 School of Engineering, Robert Gordon University, Garthdee Road, Aberdeen AB10 7GJ, UK

8 Fraunhofer IWS, Fraunhofer Institute for Material and Beam Technology, Winterbergstrasse 28, 01277 Dresden, Germany

9 Materials Performance Unit, Research and Development Centre, Saudi Aramco, Dhahran 31311, Saudi Arabia

10 Office of Research and Graduate Studies, Alfaisal University, P.O. Box 50927, Riyadh 11533, Saudi Arabia employing potentiodynamic polarization and electrochemical impedance spectroscopy. The potentiodynamic polarization results indicated that coatings produced by S-HVOF technique show lower corrosion resistance compared with the coatings produced by HVOF-JK (HVOF Jet Kote) and HVOF-JP (HVOF JP5000) techniques. Results are discussed in terms of corrosion mechanism, Bode and Nyquist plots, as well as equivalent circuit models of the coating-substrate system.

Keywords corrosion - HVOF - nanostructured coatings · S-HVOF · suspension spraying $\cdot$ WC-Co feedstock

\section{Introduction}

WC-Co hardmetal coatings prepared by high-velocity oxyfuel (HVOF) spraying are generally used in challenging tribological conditions to protect against wear, such as abrasion, contact fatigue, erosion and sliding (Ref 1-6). Previous studies have indicated that carbide size and distribution influences the mechanical properties of these coatings (Ref 7-10). However, for service in corrosive environment, either $\mathrm{Cr}_{3} \mathrm{C}_{2}$-based compositions such as $\mathrm{Cr}_{3} \mathrm{C}_{2}-\mathrm{NiCr}$, or compositions with chromium-alloyed binders such as WC-10Co4Cr and WC-NiCrBSi are the preferred technical solution (Ref 11-15). In general, understanding the corrosion behavior of HVOF-sprayed WC-Co coatings is not trivial because of their complex microstructures comprising formation of new and nonequilibrium phases, as well as partial carbide dissolution into the metal matrix. Furthermore, if the coating has been poorly deposited, it may possess some interconnected porosity, exposing the substrate to corrosion (Ref 15). All 
these microstructural features strongly affect the corrosion mechanisms.

In the case of plain WC-Co coatings, the corrosion properties can be improved by carbon loss as metallic cobalt content is decreased by the formation of $\eta$-phases, such as $\mathrm{Co}_{3} \mathrm{~W}_{3} \mathrm{C}$. However, usually this negatively influences their tribo-mechanical behavior, as it decreases the toughness of the composite (Ref 1-6). Based on a literature survey, Souza and Neville (Ref 11) described two different models of the corrosion behavior of WC-based hardmetal coatings: (a) corrosion of the matrix and release of WC grains by loss of the supporting matrix and (b) corrosion of both WC grains and the matrix; thus, loss of WC also occurs due to an electrochemical process. Later, Souza and Neville (Ref 12) compared the corrosion mechanism of an HVOF-sprayed and a stronger decarburized superdetonation-gun-sprayed (DGS) WC-CoCr coating. The lower corrosion rates in static corrosion conditions of the latter were related to the appearance of $\eta$-phases $\left(\mathrm{Co}_{3} \mathrm{~W}_{3} \mathrm{C}\right)$. Due to the presence of the $\eta$-phases as well as $\mathrm{W}_{2} \mathrm{C}$ and metallic tungsten, the corrosion mechanism of the DGS coating can be completely different. The knowledge of the electrochemical corrosion behavior of metallic tungsten is rather limited (Ref 16). It is proposed that under static corrosion conditions $\mathrm{W}$ is easily oxidized to $\mathrm{WO}_{3}$ and perhaps dissolved into $\mathrm{WO}_{4}{ }^{2-}$. Under erosion-corrosion conditions, the total volume loss of the DGS coating was higher, due to its increased brittleness caused by the carbon loss (Ref 12). The corrosion mechanism can therefore be different among the microstructural constituents, which could lead to non-uniform corrosion rates. Understanding the influence of carbon loss on the corrosion resistance for cases such as the one observed for DGS coating could be enhanced by further research. It has also been reported (Ref 13, 14) that carbide particles can cause galvanic corrosion in the matrix, or crevice corrosion can take place at the carbide-matrix interface, especially when the metal matrix has passivation capabilities.

Suspension spraying is an emerging technology to deposit nanocomposite coatings, which allows the direct injection of very fine powders (from $\mathrm{nm}$ sizes up to several $\mu \mathrm{m}$ sizes) into the plasma plume or flame, thus avoiding the necessity of powder agglomeration (Ref 17-21). Only few works regarding the spraying of hardmetal coatings using suspension spraying are known (Ref 18, 22-24). In particular, in the framework of the current work coatings were prepared by S-HVOF using aqueous suspensions of milled commercial WC-Co feedstock powder (Ref 23) and a special composite powder (Ref 24 ). In both cases, a strong non-equilibrium state of the coating combined with strong carbon loss was observed, giving rise to the formation of new phases after an additional heat treatment of the coating by HIPing (hot isostatic pressing) at $920{ }^{\circ} \mathrm{C}$. Metallic tungsten was found in the as-sprayed coating as the main phase, remaining in the coating even after the HIP treatment together with the $\eta$-phases $\mathrm{Co}_{2} \mathrm{~W}_{4} \mathrm{C}$ and $\mathrm{Co}_{6} \mathrm{~W}_{6} \mathrm{C}$ with some $\mathrm{WC}$ and $\mathrm{W}_{2} \mathrm{C}$ (Ref 22). These coating phase compositions correspond to an intermediate state toward the thermodynamic equilibrium for the chemical composition formed after spraying as confirmed by thermodynamic calculations (Ref 22). Extensive TEM investigations of both as-sprayed and HIPed coatings have shown that these and some other carbide phases occurring in very small amounts are nanosized. However, TEM studies do not allow a full description about a nanocrystalline or amorphous state of all constituents over the entire volume of the coating. The sliding wear performance of these assprayed and heat-treated coatings was also extensively studied (Ref 22-24). These coatings are also significantly different by their chemical and phase compositions as well as microstructures from conventional HVOF-sprayed WCCo coatings (Ref 22-24).

None of these previous studies have considered the corrosion performance of suspension-sprayed nanocomposite coatings. The aim of the current investigation was therefore to compare the corrosion performance of these coatings and compare it with conventional HVOF coatings deposited using Jet Kote (HVOF-JK) and JP5000 (HVOFJP) guns, all in as-sprayed condition. As the application of these coatings requires wear and high-stress contact fatigue in corrosive environments, the choice of substrate becomes important, as it not only need to be corrosion resistant, but also sufficiently high strength to support the coating under mechanical stress. The important role of substrate in supporting the high stress in the coating was well demonstrated in previous studies (Ref 4, 5, 25-27). Hence, a highchromium AISI 440C substrate was chosen for this investigation.

\section{Experimental}

\section{Coating Deposition}

For corrosion studies described in this paper, coatings were prepared by suspension HVOF (S-HVOF) spraying, using an agglomerated and sintered WC-12 wt.\% Co feedstock powder DTS W653-20/5 (Fujimi Corp., Japan) with submicron WC grains. In order to adapt the particle size for suspension preparation, the powder was milled in a planetary ball mill as previously reported by Ahmed et al. (Ref 23) and aqueous suspensions consisting of $25 \mathrm{wt} . \%$ solid content and 75 wt.\% deionized water were developed. S-HVOF spraying was conducted using a modified HVOF (TopGun, GTV mbH, Luckenbach, Germany) spray process using ethene as the fuel gas (Ref 23). Coatings sprayed 
with condition \#2 as previously described in detail (Ref 23) were used in this study.

In order to compare the corrosion performance of nanocomposite S-HVOF coatings with conventional coatings, HVOF-JK (Jet Kote) and HVOF-JP (JP5000) coatings by means of WC-12 wt.\% Co agglomerated and sintered powders were prepared, as previously reported (Ref $23,24)$. Industrially optimized coating process parameters were used for these conventional HVOF coatings. All coatings were deposited on AISI 440C stainless steel disks of $31 \mathrm{~mm}$ diameter and $6 \mathrm{~mm}$ thickness. Substrate material for all coatings was grit blasted prior to the coating deposition. Hardness values of all coatings are listed in Table 1 (Ref 23, 24).

\section{Microstructural Evaluations}

The morphology and the chemical composition of the samples were determined by scanning electron microscopy (SEM) using a $20 \mathrm{kV}$ JEOL 840A SEM equipped with an OXFORD INCA 300 EDS analyzer. The phase composition for as-sprayed condition and after corrosion attack was studied using a two-cycle Rigaku Ultima + diffractometer (40 kV, $30 \mathrm{~mA}, \mathrm{Cu}-\mathrm{K} \alpha$ radiation with $\lambda=1.5406 \AA$ ).

\section{Corrosion Investigations}

The corrosion performance-early stages of corrosion of AISI 440C stainless steel and the as-sprayed coatings was examined in a $3.5 \mathrm{wt} \% \mathrm{NaCl}$ aqueous solution at room temperature $\left(\sim 25^{\circ} \mathrm{C}\right)$. Saturated calomel electrode (SCE) and platinum electrode of $2 \mathrm{~cm}^{2}$ exposed area were used as reference and auxiliary (counter) electrode, respectively. Specimens for corrosion experiments were cut and sealed (using epoxy resin) leaving an area of $1 \mathrm{~cm}^{2}$ exposed to $\mathrm{NaCl}$ solution. The experimental setup of the electrochemical corrosion apparatus was in compliance with ASTM G 69-12 and ASTM G71-81 standards. The electrochemical properties of the samples were assessed experimentally by potentiodynamic polarization and electrochemical impedance spectroscopy (EIS) measurements. All electrochemical measurements were taken using a Voltalab PGZ 402 advanced electrochemical system. Prior to potentiodynamic polarization and EIS measurements,

Table 1 Coating hardness values

\begin{tabular}{lc}
\hline Spray process & $\begin{array}{c}\text { Microhardness } \\
\mathrm{HV}_{2.9 \mathrm{~N}}\end{array}$ \\
\hline S-HVOF (TopGun) & $998 \pm 73$ \\
HVOF-JK (Jet Kote) & $924 \pm 127$ \\
HVOF-JP (JP5000) & $1118 \pm 131$ \\
\hline
\end{tabular}

the working electrode was immersed into the test solution at open-circuit potential (OCP) for $60 \mathrm{~min}$ to attain a steady-state condition. Potentiodynamic polarization measurements were taken from $-500 \mathrm{mV}$ versus the OCP $\left(E_{\mathrm{OCP}}\right)$ to $+700 \mathrm{mV}$ versus $E_{\mathrm{OCP}}$ with scanning rate of $0.5 \mathrm{mV} / \mathrm{s}$. The current density values were normalized to the exposed surface area. EIS was carried out after 60-min OCP measurements at each resulted $E_{\mathrm{OCP}}$ value for every specimen in the frequency range of $0.01 \mathrm{~Hz}-10 \mathrm{kHz}$ using a $10 \mathrm{mV}$ peak-to-peak voltage excitation. The reproducibility of the electrochemical test was verified by carrying out three measurements for each coated sample. The corresponding mean values were used in the relative diagrams. Polarization curves and EIS results were analyzed using Voltamaster 4 and EIS Spectrum Analyser 1.0 program (using Powell's algorithm), respectively.

\section{Results and Discussion}

The microstructural features of the as-sprayed coatings have been discussed in detail in previous publications (Ref $23,24)$. The focus of the discussion here is to compare the as-sprayed microstructure before and after corrosion test.

\section{Microstructure Before Corrosion Test}

\section{S-HVOF Coating}

The average coating thickness before corrosion test was $134 \mu \mathrm{m}$. No cracks were found but the coating cross section is characterized by many pores and lamellae formations (Fig. 1a). On the polished surface, numerous large pores with diameter up to $2.5 \mu \mathrm{m}$ were observed (Fig. 1b). EDS analysis on the denoted surface area revealed that it contains 25 at.\%. Co and 75 at.\% W. Carbon was not detectable from the EDS analyzer because the EDS detector had Be window which absorbs low-energy x-rays; thus, only elements with atomic number greater than carbon were detectable.

It is also known from carbon and oxygen analysis that this coating is strongly decarburized, which is the reason for appearance of metallic tungsten (Ref 22, 23).

\section{HVOF-JK Coating}

The average coating thickness before corrosion was $326 \mu \mathrm{m}$. No cracks or large connected pores were found. Its cross section is characterized by less pores compared with S-HVOF and lamellae formations (Fig. 2a) which form longitudinal dark formations in S-HVOF coatings. The polished surface morphology is composed by characteristic angular WC grains (light areas) embedded in a Co- 
Fig. 1 Cross-sectional (a) and (b) polished plane-view SEM micrograph of the as-sprayed S-HVOF sample
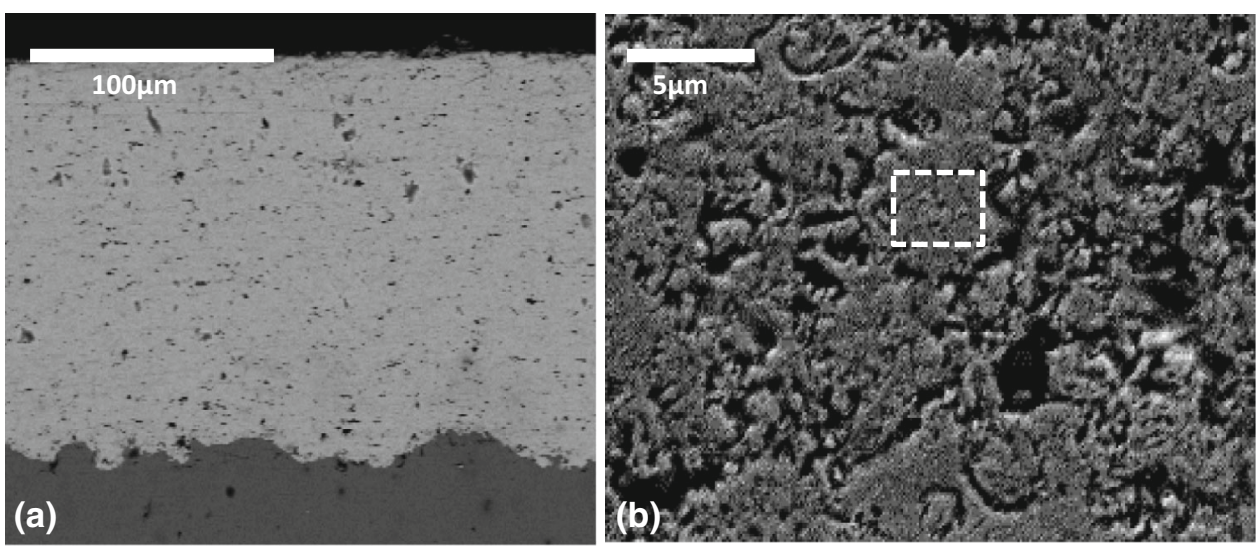

Fig. 2 Cross-sectional (a) and (b) polished plane-view SEM micrograph of the as-sprayed HVOF-JK sample
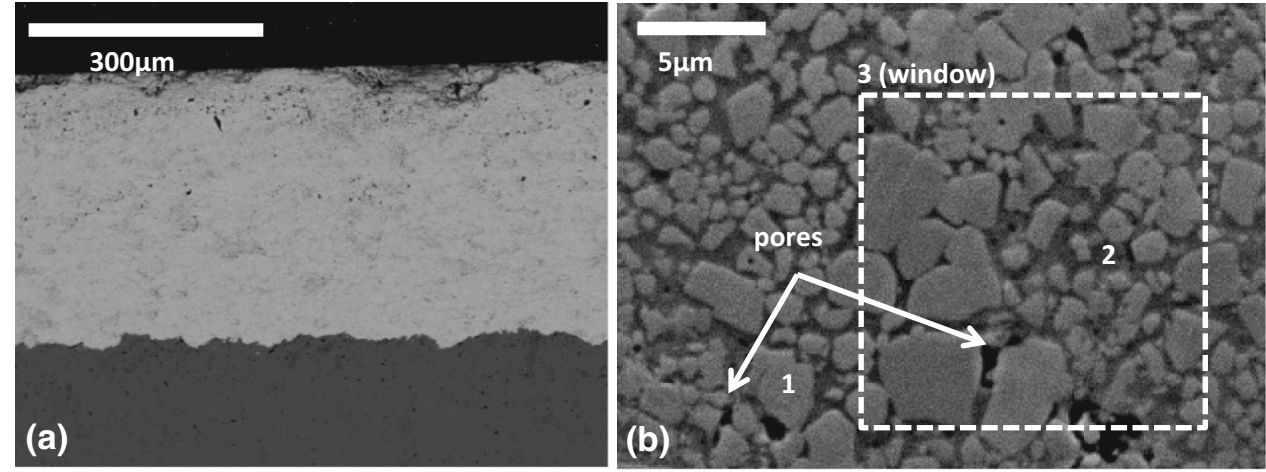

Fig. 3 Cross-sectional (a) and (b) polished plane-view SEM micrograph of the as-sprayed HVOF-JP sample
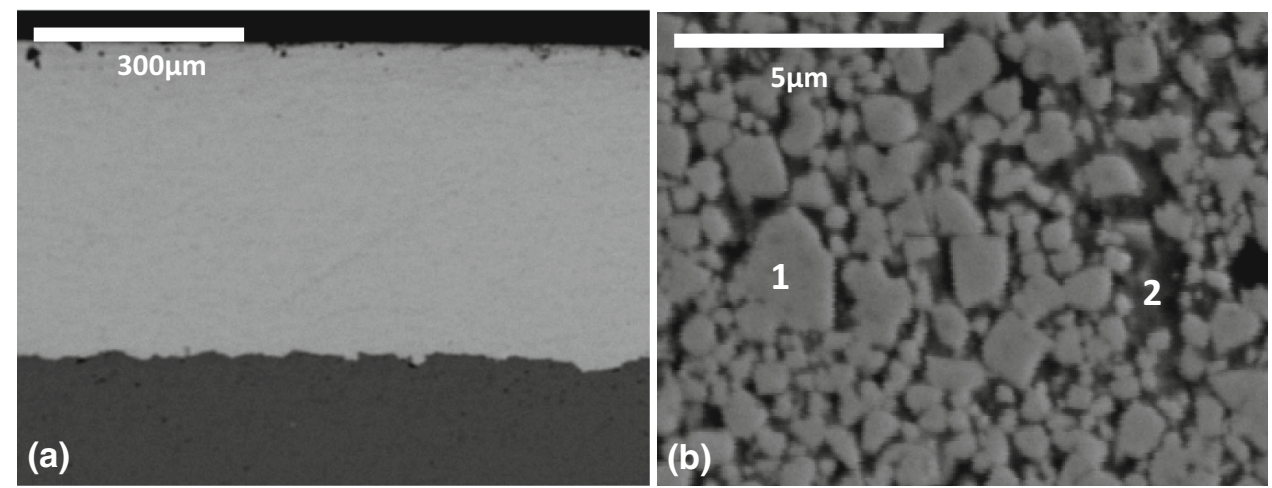

W matrix (darker areas) (Fig. 2b). This was verified by the EDS analysis denoted in Fig. 2(b) which revealed that area 1 is mainly composed of $\mathrm{W}$ while area 2 is composed of 28 at.\% $\mathrm{Co}$ and 72 at.\% W. The denoted window in Fig. 2(b) was found to contain 90 at.\% W and 10 at.\% Co in total. The number of large pores is significantly less compared with the S-HVOF coating.

\section{HVOF-JP Coating}

The average coating thickness before corrosion was $383 \mu \mathrm{m}$. No cracks or large connected pores were found. Its cross section shows relatively lower pore content between the three coatings (Fig. 3a). The pores are mainly restricted to the upper region of the coating, while lamellae formations are hardly observed. The polished surface morphology is similar to HVOF-JK with micron-sized WC particles embedded in Co-W matrix (Fig. 3b). EDS results on the denoted areas in Fig. 3(b) revealed that area 1 is mainly composed by W while area 2 is composed of 63 at.\% Co and 37 at.\% W.

\section{Microscopic Investigation and Identification of the Corroded Samples}

After potentiodynamic measurements, the thickness of the corroded S-HVOF coating (Fig. 4a) still corresponds to the 
Fig. 4 Cross-sectional (a) and plane-view (b) SEM micrograph of the corroded S-HVOF sample
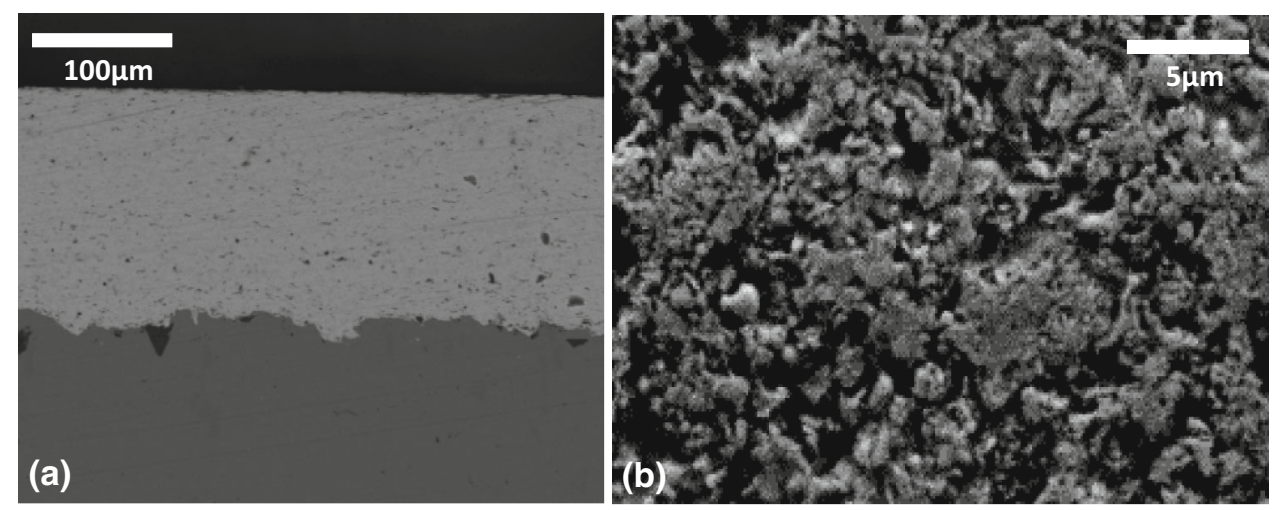

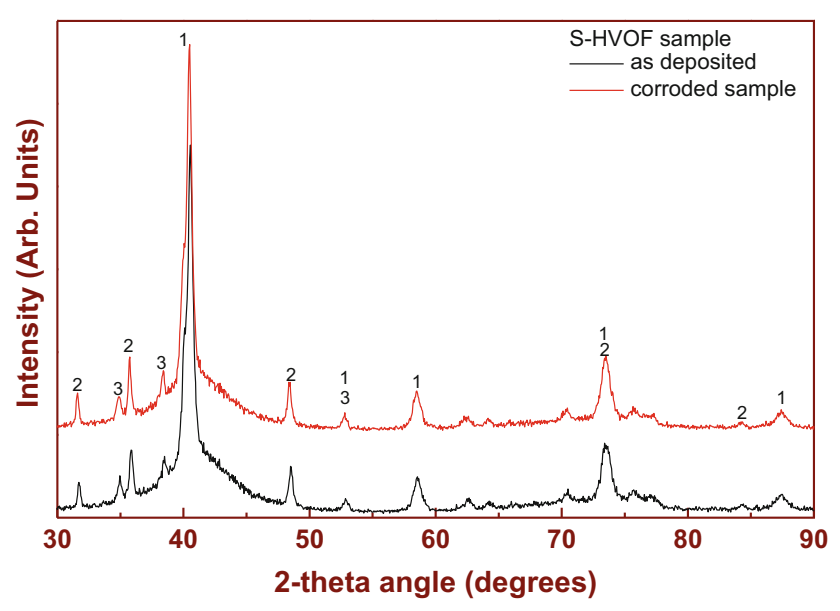

Fig. 5 XRD patterns of the as-deposited and corroded S-HVOF sample (designation of the peaks: $1-\mathrm{W} ; 2-\mathrm{WC}, 3-\mathrm{W}_{2} \mathrm{C}$ )

as-sprayed state (Fig. 1a). However, in the plane-view SEM micrograph (Fig. 4b), the surface roughness was found to increase as more craters are observed to have been formed compared with the as-sprayed state (Fig. 1b). This can be attributed to some material loss due to corrosion. EDS analysis performed on different areas of the surface showed that no corrosion products could be detected.

The above remark was confirmed also with $\mathrm{x}$-ray diffraction (XRD) analysis. As shown in the comparative XRD image (Fig. 5), the patterns of the as-deposited and of the corroded samples have the same identified compounds. There was only one area where the coating was found to have collapsed (Fig. 6a). As presented in the corresponding figure, the coating in that particular area has cracked. EDS analysis (Table 2) performed on the areas denoted in Fig. 6(b) showed that area \#2 corresponds to a non-damaged region and area \#1 to the most corroded region, as per the relatively higher concentrations of $\mathrm{Cl}, \mathrm{Na}$ and $\mathrm{O}$. Some $\mathrm{Fe}$ was also traced area \#1, which means that the corrosive medium has reached the substrate. Finally, area \#3 corresponds to a less corroded area because of the $\mathrm{Cl}, \mathrm{Na}$ and $\mathrm{O}$ amounts traced.
After potentiodynamic measurements, the thickness of the corroded HVOF-JK sample remained nominally stable compared with the as-deposited one in Fig. 2(a) (Fig. 7a). In some areas on the surface, several corroded regions were observed (dark areas at the top coating areas) where the pore network was enlarged by the effect of the corrosive environment, leaving easy path for its penetration from the corrosive agents. Particularly, in these areas the presence of $\mathrm{Cl}$ and $\mathrm{Na}$ was detected with EDS up to a depth of $80 \mu \mathrm{m}$ (inset image of Fig. 7a). In the plane-view SEM micrograph (Fig. 7b), numerous craters were observed which in some cases have significant depth (Fig. 7c). The material loss at these areas was extreme as EDS in these craters revealed the existence of $\mathrm{Fe}(21$ at. $\%$. $\mathrm{O}, 8.5$ at.\% $\mathrm{Na}, 43$ at.\% Cl, 10.5 at.\% $\mathrm{Fe}, 6$ at.\% Co, 11 at.\% W). These deep craters were found at spotted areas and do not characterize the general situation of the sample after corrosion, and hence, they were not found in the cross-sectional image. However, their existence can be considered in order to evaluate the corrosion resistance of HVOF-JK coatings. Finally, some isolated areas were found containing high concentrations of $\mathrm{NaCl}$ (denoted areas in Fig. 7d). Their existence is probably the result of some corrosive agent which has adhered on the surface with the help of the preexisting pores.

In the comparative XRD image (Fig. 8), the patterns of the as-deposited and of the corroded HVOF-JK samples are similar to the same identified compounds, which indicates that the particular corroded areas described above are very limited and are an exception from the coating general situation. However, some reduction in the area of the "amorphous/nanocrystalline" hump is visible at around $42^{\circ}$ after corrosion test. This slight reduction could be a result of dissolution of the "amorphous/nanocrystalline" materials during the corrosion process.

The corroded HVOF-JP sample, similar to the previous samples, maintains its initial thickness after deposition compared with the as-deposited one in Fig. 3(a) (Fig. 9a). EDS analysis performed on the cross section revealed in some cases significant penetration of the corrosion agents 
Fig. 6 Plane-view SEM micrographs of the collapsed corroded areas of S-HVOF sample in different magnifications
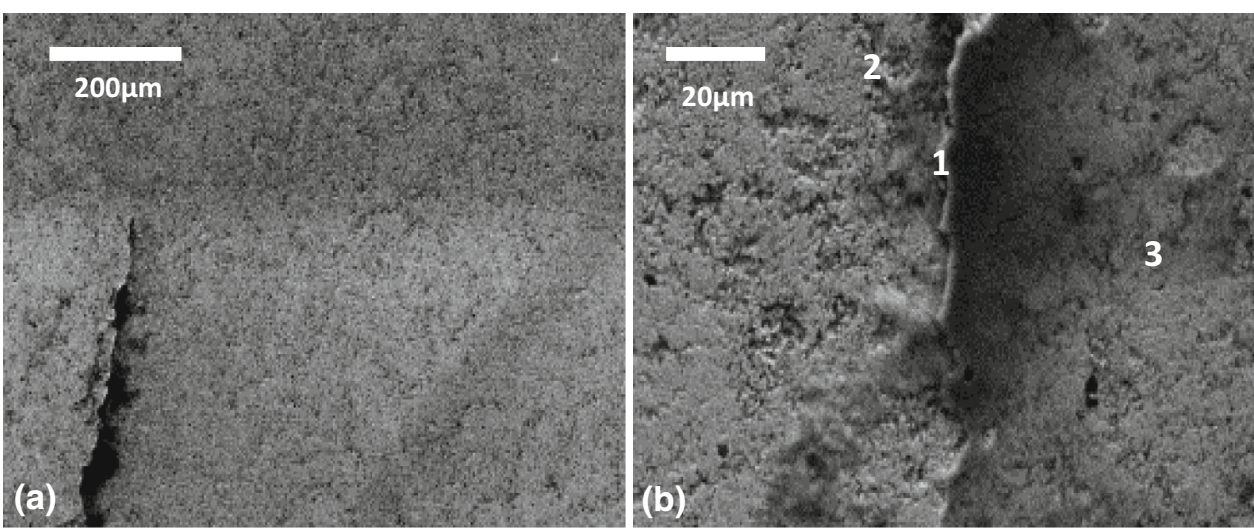

Table 2 EDS results from the denoted areas in Fig. 6(b). All values are in at.\%

\begin{tabular}{lrllrrr}
\hline Area nr. & $\mathrm{O}$ & $\mathrm{Na}$ & $\mathrm{Cl}$ & $\mathrm{Fe}$ & $\mathrm{Co}$ & $\mathrm{W}$ \\
\hline 1 & 42.7 & 2.0 & 3.6 & 37.2 & 1.5 & 12.9 \\
2 & 3.7 & 0 & 0 & 0.3 & 5.9 & 90.1 \\
3 & 14.1 & 0.6 & 0.3 & 0.6 & 4.7 & 79.7 \\
\hline
\end{tabular}

in the coating. Particularly in the EDS analysis of Fig. 9(b), which is a magnification of the surface area of Fig. 9(a), amounts of $\mathrm{Cl}$ and $\mathrm{Na}$ were traced up to $38 \mu \mathrm{m}$ inside the coating while oxygen has penetrated the coating for more than $102 \mu \mathrm{m}$. The oxides are mainly located in the dark areas in the coating as denoted in Fig. 9(b).

In the plane-view SEM micrograph (Fig. 10a), the preferential attack of the binder matrix by the corrosive media is revealed. The attack on WC grains is minimal (Fig. 3b). It is probable that a galvanic cell is created between the two areas that result in the accelerated corrosion of the matrix as noted in previous sections. Moreover, in some areas (Fig. 10b) there was also some evidence of removal of the WC. EDS on these areas revealed the presence of high oxygen concentrations (average 20 at.\%.) together with $\mathrm{Na}$ and $\mathrm{Cl}$ (average 8 at.\% for each one).

In the comparative XRD pattern (Fig. 11) of the asdeposited and the corroded HVOF-JP sample, no corrosion products were identified, which implies that their concentration is very low and out of the detection limits of the method or that the small amount of corrosion products that may have formed are amorphous. Furthermore, these patterns were similar to the pattern of the HVOF-JK coating. The comparison shows the attack on the binder, as the "amorphous/nanocrystalline hump" at around $42^{\circ}$ disappeared in the corroded sample.

\section{Corrosion Test Results}

\section{Potential and Polarization Measurements}

The open-circuit potential (OCP) of coated and uncoated samples (versus SCE; saturated calomel electrode) in 3.5 wt.\% $\mathrm{NaCl}$ aqueous solution during a period of $60 \mathrm{~min}$ is shown in Fig. 12. OCP measurements stabilize after 30 min of exposure. It can be seen (Fig. 12) that compared with $440 \mathrm{C}$ stainless steel $\left(E_{\mathrm{OCP}}=-443 \pm 10 \mathrm{mV}\right)$ all coated samples had more electronegative values (for S-HVOF, $\quad E_{\mathrm{OCP}}=-550.3 \pm 20 \mathrm{mV}$; for HVOF-JK, $E_{\mathrm{OCP}}=-466 \pm 10 \mathrm{mV}$ and for HVOF-JP $E_{\mathrm{OCP}-}$ $=-457 \pm 10 \mathrm{mV}$ ) with the most electronegative $E_{\mathrm{OCP}}$ reported for S-HVOF-coated samples. These measurements show that the coated samples (especially S-HVOF coating) are more active (or anodic) in comparison with the stainless steel substrate. This indicates that the substrate is nobler than the coatings, and thus, taking only thermodynamic considerations, the coating corrosion will most likely occur in preference to the substrate when the substrate and the coating are in electrolytic contact.

The potentiodynamic polarization diagrams of coated and uncoated samples are presented in Fig. 13. In the cathodic part of the polarization curves, two regions can be observed that probably represents (1) the mass transfer dominated reduction of dissolved oxygen in the solution and (2) the charge transfer controlled evolution of hydrogen from the aqueous media at more negative potentials. The corrosion potentials $\left(E_{\text {corr }}\right)$, corrosion currents $\left(i_{\text {corr }}\right)$ and Tafel slopes (ba, bc) of S-HVOF-, HVOF-JK- and HVOF-JP-coated samples together with the bare stainless steel substrate $440 \mathrm{C}$ are summarized in Table 3. These parameters were estimated by taking into consideration several zones from 50 to $200 \mathrm{mV}$ (away from $E_{\text {corr }}$ ) to optimize the fitting of the Tafel slopes. The $E_{\text {corr }}$ values (Table 3) of the coated samples are more electronegative compared with the relevant $E_{\mathrm{OCP}}$ values, meaning that the substrate is nobler than the coatings. Furthermore, $i_{\text {corr }}$ for 
Fig. 7 Cross-sectional (a) and plane-view SEM micrographs of the corroded HVOF-JK sample (b: general view, c: area with deep craters, d: area with noticeable $\mathrm{Na}$ and $\mathrm{Cl}$ )

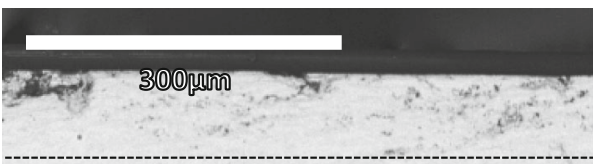

Depth limit of the corroded area
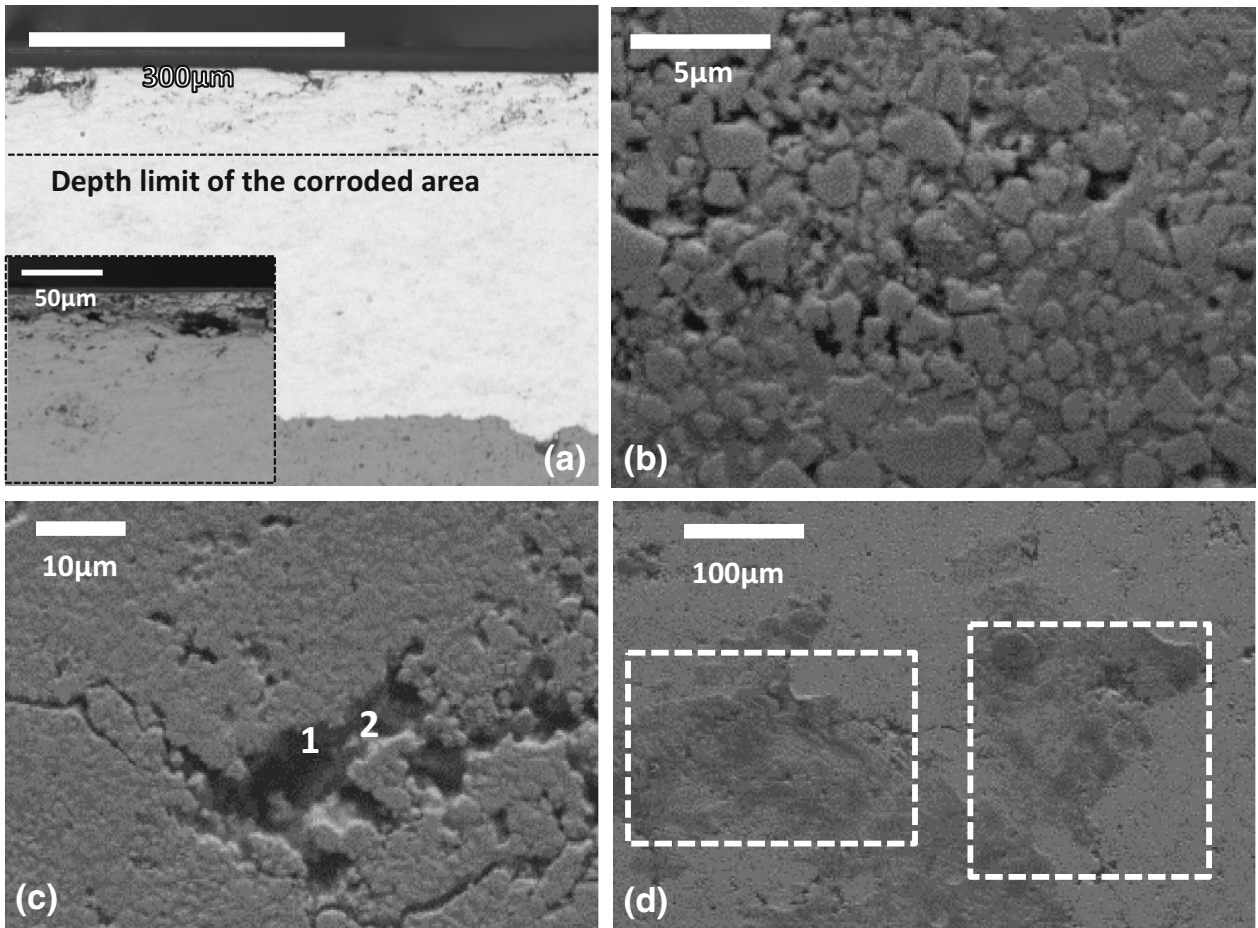

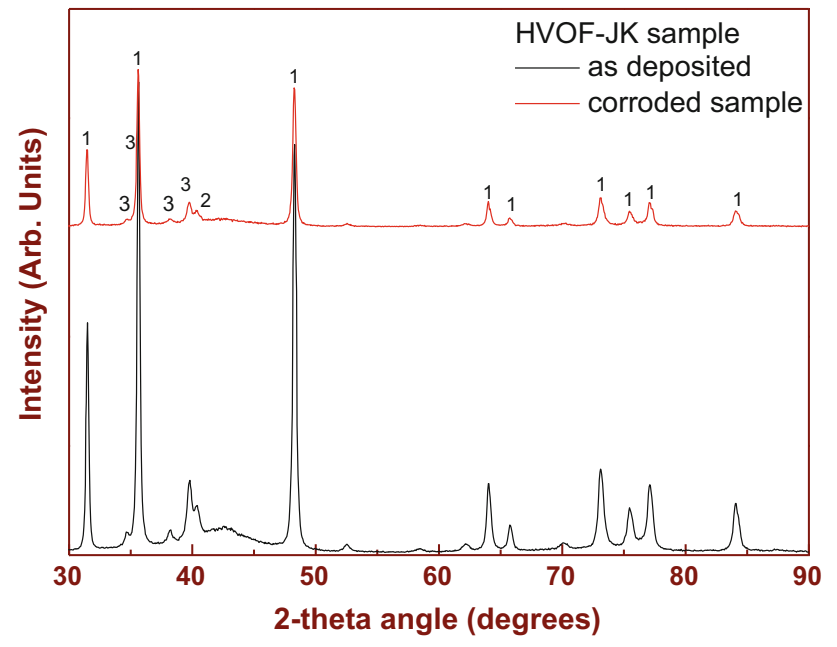

Fig. 8 XRD patterns of the as-deposited and the corroded HVOF-JK sample (designation of the peaks: $1-\mathrm{WC} ; 2-\mathrm{Co}_{3} \mathrm{~W}_{3} \mathrm{C} ; 3-\mathrm{W}_{2} \mathrm{C}$ )

S-HVOF is higher compared with other coated and uncoated samples. In fact, corrosion resistance cannot be reliably assessed through the measurement of the corrosion potential alone. By examining the anodic region for the substrate $440 \mathrm{C}$ stainless steel, it can be observed that there is active dissolution (significant increase in the corrosion current) beyond $\sim-300 \mathrm{mV}$ versus SCE. One could assume this as critical pitting potential (Epit). Epit is the least anodic potential at which pits can form. At this limiting potential, the metal ions in solution are in equilibrium with the metal oxide. Beyond this potential, the current rises and at a potential of $\sim-100 \mathrm{mV}$ versus SCE the current begins to stabilize whereas at $\sim 0 \mathrm{mV}$ versus SCE a stable corrosion current density value is reached, possibly due to the formation of a stable oxide layer. As for the coated samples, the entire anodic region is an active dissolution region, without the existence of a pitting potential, reaching a relatively steady corrosion current. Anodic reaction products cannot enter the solution faster, and mass transfer limited current density is reached (Fig. 13).

From the potentiodynamic polarization measurements, it was found that the corrosion current densities $i_{\text {corr }}$ of 440C stainless steel and HVOF-JK- and HVOF-JP-coated samples have similar values (Table 3). It should be noted that since no microcracks or large surface-connected pores can be observed as mentioned in Section "Microstructure Before Corrosion Test" for coated samples, the polarization plots (Fig. 13) possibly reveal the intrinsic corrosion resistance of the coatings. Based on this assumption, it can be suggested that the corrosion performance of coated samples is mainly affected by microgalvanic phenomena that occur between two distinct phases, existence of distinct grain boundaries and the presence of pores in the coating (Fig. 1 and 2). In plain WC-Co coatings, WC grains act as cathode (since in artificial seawater WC grains are almost inert) in contact with $\mathrm{Co}$, which acts as anode (oxidation of $\left.\mathrm{Co}: \mathrm{Co}=\mathrm{Co}^{2+}+2 \mathrm{e}^{-}\right)(\operatorname{Ref} 28)$.

Enhanced Co dissolution can occur due to the unfavorable surface ratio of anodic to cathodic sites. Furthermore, the presence of any pores in the coatings (higher for S-HVOF coating and lower for HVOF-JP coating) 
Fig. 9 Cross-sectional SEM micrograph of the corroded HVOF-JP sample (a) and magnification of the surface area (b)
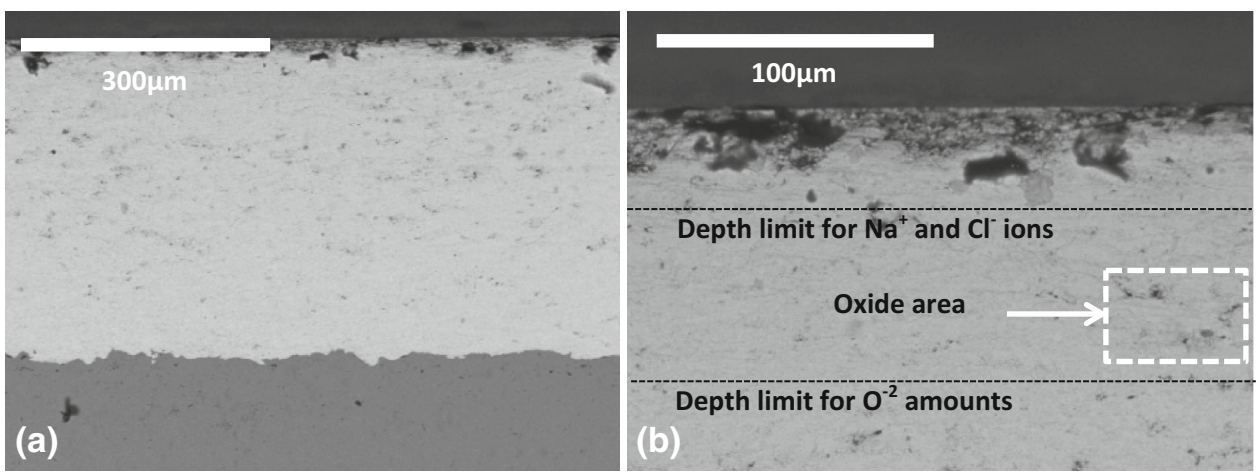

Fig. 10 Plane-view SEM micrograph of the corroded HVOF-JP sample (a) and magnification of the denoted area (b)
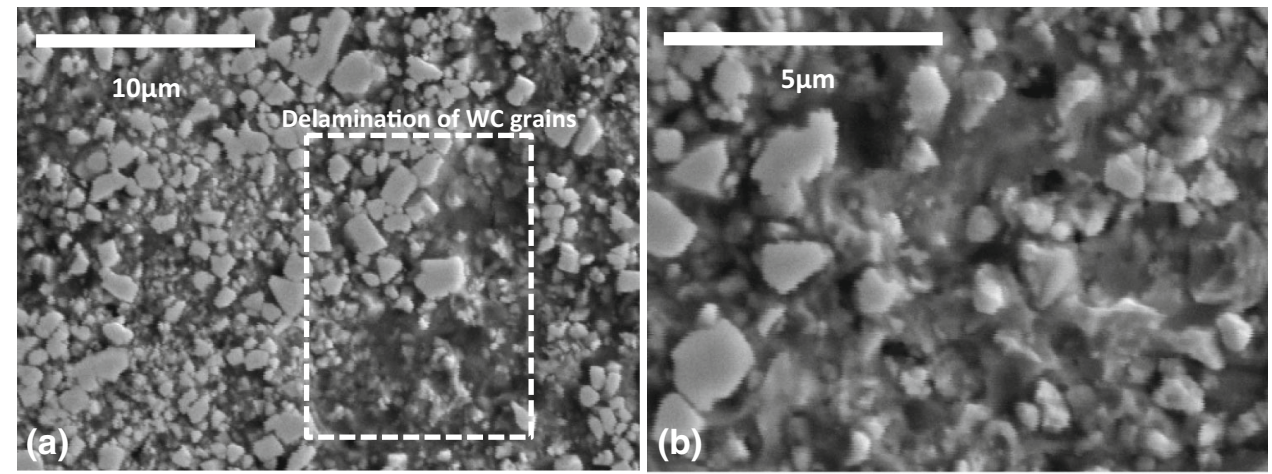

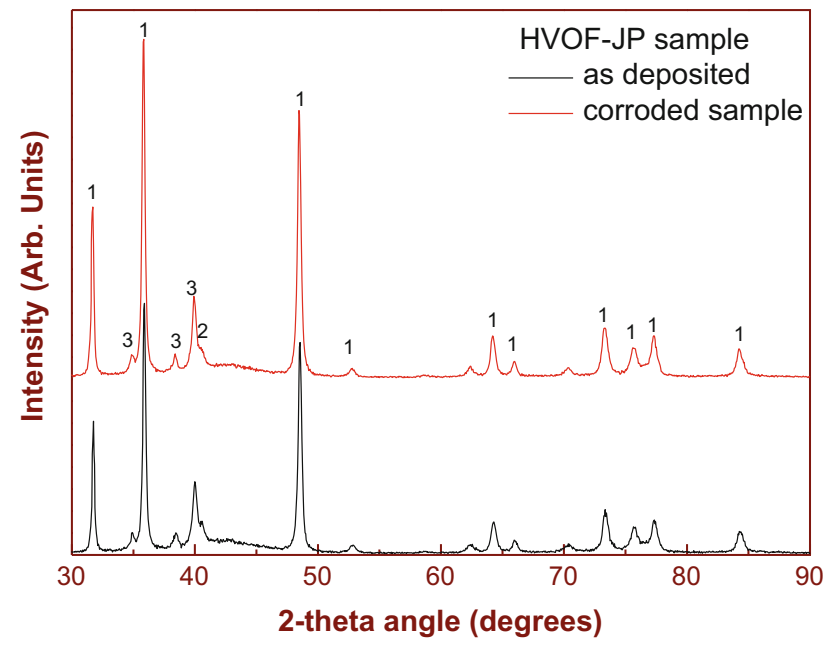

Fig. 11 XRD patterns of the as-deposited and the corroded HVOF-JP sample (designation of the peaks: $1-\mathrm{WC} ; 2-\mathrm{Co}_{3} \mathrm{~W}_{3} \mathrm{C} ; 3-\mathrm{W}_{2} \mathrm{C}$ )

certainly plays an important role in the evolution of corrosion (as pores are present in thermal spray coatings by nature), especially in $\mathrm{Cl}^{-}$environments. These pores offer sites with localized concentration effects where electrochemical reactions are favored (Ref 29). The content of nanocrystalline and amorphous constituents in the S-HVOF coating is larger than in the case of the conventional coatings. Only after a heat treatment (HIPing at $920{ }^{\circ} \mathrm{C}$ ), $\eta$-phases are the major phases, besides metallic tungsten and some $\mathrm{WC}$ and $\mathrm{W}_{2} \mathrm{C}$ (Ref 22-24). Thus, the nature of this amorphous/nanocrystalline phase is currently not known. The significant difference between the S-HVOF coating (higher corrosion current $i_{\text {corr }}$-Table 3 ) compared with the other coatings can be explained somewhat by the classical corrosion theory where nanostructured materials accelerate any electrochemical process by forming more local micro-electrochemical cells across higher density of grain boundaries and also by the relatively higher pore content (Fig. 1 and 2) (Ref 28, 29).

A higher particle/matrix boundary density and thus a larger fraction of materials that undergoes anodic dissolution are a characteristic of nanostructured coatings in comparison with coatings with larger grains. The active dissolution of the binder phase has been reported before (Ref 30), and it would appear that smaller grains, resulting in larger number of grain boundaries, would have relatively higher binder dissolution. This is most likely the case for S-HVOF coating which shows fine-scale grains. The understanding of selective corrosion of more anodic phases due to the changes occurring during the spray process is important. During spraying, phase transformation results in the formation of coating with different composition than that of the feedstock. The XRD data show the formation of elemental tungsten and $\mathrm{W}_{2} \mathrm{C}$ in the S-HVOF coating with some remaining $\mathrm{WC}$, and predominant amorphous/nanocrystalline material, which transforms largely 
Fig. 12 OCP measurements of S-HVOF-, HVOF-JK- and HVOF-JP-coated samples together with the bare substrate (440 C stainless steel substrate)
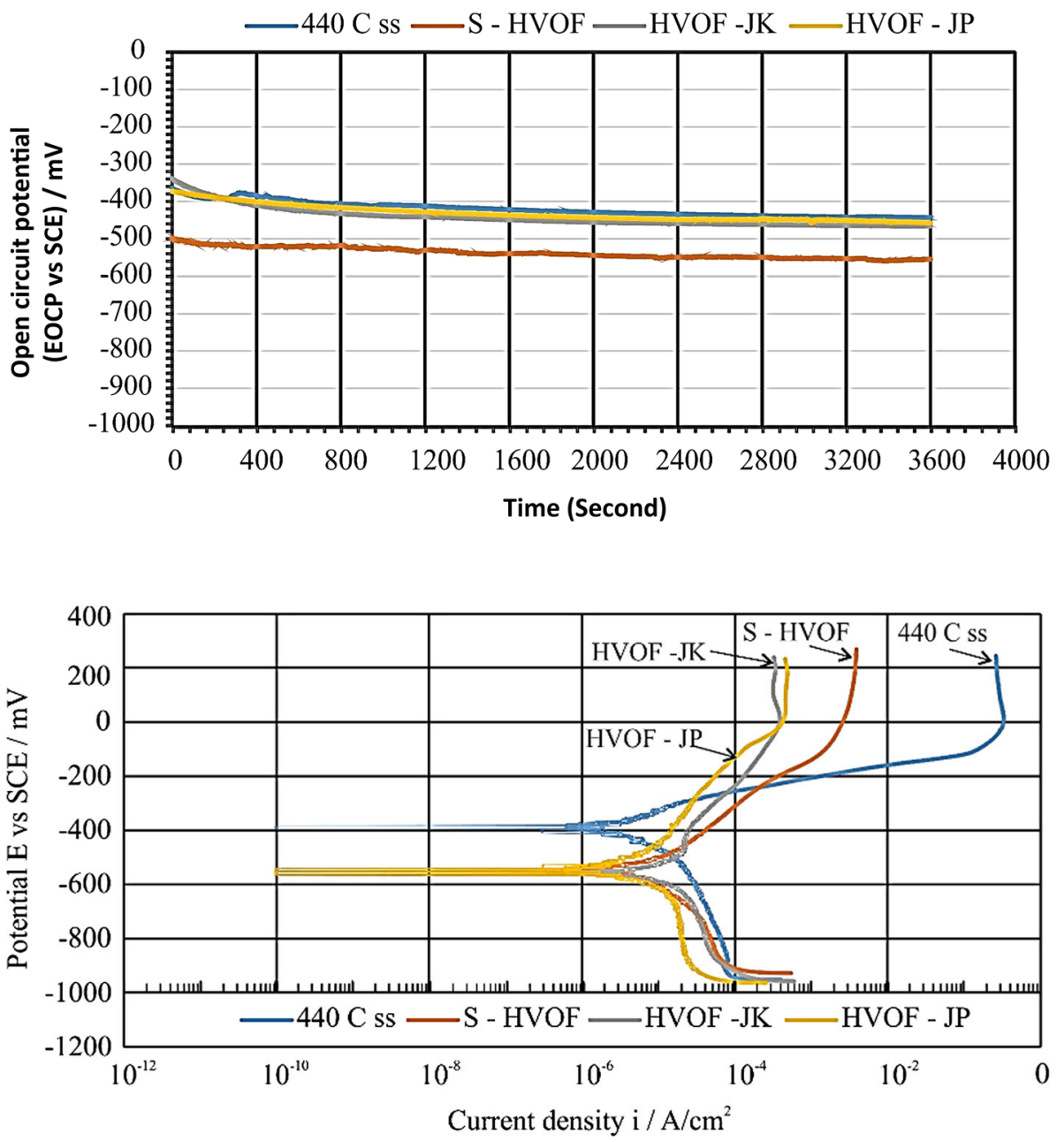

Fig. 13 Potentiodynamic polarization measurements of S-HVOF-, HVOF-JK- and HVOF-JP-coated samples together with the bare substrate (440C ss)
Table 3 Corrosion potentials $\left(E_{\text {corr }}\right)$, corrosion currents $\left(i_{\text {corr }}\right)$ and Tafel slopes $(\mathrm{ba}, \mathrm{bc})$ of S-HVOF-, HVOF-JK- and HVOF-JP-coated samples together with the bare substrate (440C ss)

\begin{tabular}{lcccc}
\hline Sample & $i_{\text {corr }}, \mu \mathrm{A} / \mathrm{cm}^{2}$ & $E_{\text {corr, }} \mathrm{mV}$ versus SCE & ba, $\mathrm{mV}$ & $\mathrm{bc}, \mathrm{mV}$ \\
\hline 440C substrate & $1.8 \pm 0.3$ & $-396.7 \pm 20$ & 67.8 & -94.1 \\
S-HVOF & $2.5 \pm 0.2$ & $-551.4 \pm 20$ & 71.9 & -94 \\
HVOF-JK & $2.3 \pm 0.3$ & $-563 \pm 20$ & 79.5 & -76.6 \\
HVOF-JP & $2.0 \pm 0.3$ & $-553 \pm 20$ & 99.1 & -71 \\
\hline
\end{tabular}

into $\eta$-phases during a heat treatment (Ref 22-24). Thus, this multi-phase system within the corroding matrix could lead to non-uniform corrosion rates. Both conventional $\mathrm{HVOF}$ coatings comprise of $\mathrm{WC}, \mathrm{Co}_{3} \mathrm{~W}_{3} \mathrm{C}$ and $\mathrm{W}_{2} \mathrm{C}$ crystalline phases with some amorphous/nanocrystalline material. This along with the micrographs of the coating cross sections indicates that the S-HVOF is much strongly decarburized than the conventional coatings. This could indicate that an electrical contact between WC and Co does not exist. The presence of tungsten in the S-HVOF coating is also worth mentioning here as this could contribute to accelerated dissolution. The effect of different phases on the corrosion behavior was evident during anodic polarization experiments. Corrosion of WC-Co alloy begins with the possible active dissolution of binder phase in preferential sites, such as areas adjacent to the WC grains and/or WC/Co interfaces (Ref 31). In the case of HVOF-JK and HVOF-JP, relatively larger WC grain size can result in improved corrosion resistance owing to the reduction in the number of the $\mathrm{WC} / \mathrm{Co}$ interfaces. Co is known to form $\mathrm{Co}(\mathrm{OH})_{2}$ in neutral solutions which is relatively insoluble $\left(K_{\mathrm{sp}} \sim 2.5 \times 10^{-16}\right.$; (Ref 32$\left.)\right)$ and hence perceived to be reasonably protective. If the presence of Co was responsible for greater corrosion resistance, then small WC grain size would have facilitated the improvement of corrosion resistance owing to the increase in the number of 
the WC/Co interfaces (Ref 33). However, this is not the case. The corrosion susceptibility as indicated by $i_{\text {corr }}$ values shows that the corrosion tendency of S-HVOF is greater than that of HVOF-JK and HVOF-JP. If the binder phase was not responsible for the corrosion performance, a greater corrosion resistance for S-HVOF could be expected. Another factor to consider is the presence of various phases in the coatings. This is discussed in the next section.

\section{Influence of Microstructural Phases on Corrosion}

In order to understand the corrosion performance of the coatings containing different phases, one needs to understand the interactions between the various phases present. For pure specimens of Co and WC, Co shows increasing dissolution rates toward the acidic domain, while WC is least stable in alkaline solution (Ref 34). It would thus be difficult to state the response of WC-Co system in a nearneutral media without experimental data. Nonetheless, from the experiments carried out, it is clear that the overall electrochemical behavior of WC-Co coatings is determined by the interface or the binder phases present at boundary between the WC and Co. Due to the possible active dissolution of the binder phases on the surface, the WC grains become dislodged, which can cause removal of WC and thus show pits in the alloy (Ref 35). The occurrence of pseudo-passivity at high anodic potentials is a known phenomenon for cemented carbides in acidic solution (Ref $36,37)$. This is often associated with the accumulation of the less soluble $\mathrm{WO}_{3}$ and the filling of the gaps through the removal of $\mathrm{WO}_{3}$ (Ref 35). Another aspect which needs to be considered is the presence of heterogeneities in the metal matrix that can contribute to preferential sites for corrosion activation. In the XRD pattern, a broad band exists in the $35^{\circ}<2 \theta<48^{\circ}$ range for the S-HVOF sample, which has been attributed to the formation of an amorphous/nanocrystalline material, because splat quenching drastically hampers crystal growth, thus hindering crystals formation or causing the formation of nanocrystals in the S-HVOF coating.

The presence of metallic tungsten in the S-HVOF coating possibly played a role in its corrosion performance. Data on the corrosion performance of metallic tungsten in near-neutral $\mathrm{pH}$ solutions are rare. However, some conclusions can be drawn from the work carried out by Kelsey (Ref 38). According to this work, it would appear that dissolution of metallic tungsten during anodic polarization in an aqueous media occurs following the mechanism below:

$$
W+4 \mathrm{OH}^{-} \rightarrow \mathrm{WO}_{2}+4 \mathrm{e}+2 \mathrm{H}_{2} \mathrm{O} .
$$

The $\mathrm{WO}_{2}$ formed gives rise to $\mathrm{WO}_{3}$ at lower $\mathrm{pH}$ via the formation of intermediate $\mathrm{WO}_{3} \mathrm{H}$, which is considered the rate determining step. The cathodic reaction in the above case can be the reduction of dissolved oxygen which would give rise to $\mathrm{OH}^{-}$ions. In the absence of dissolved oxygen, the cathodic reaction shifts to the water splitting, which, in aerated systems, is thermodynamically less favorable. The tests carried out in the work presented here were performed in $3.5 \mathrm{wt} . \% \mathrm{NaCl}$ at room temperature in air, and in such environments, near-neutral $\mathrm{pH}$ is likely. However, the consumption of the cathodically generated $\mathrm{OH}^{-}$by the reaction presented above would reduce the $\mathrm{pH}$ at least locally in the vicinity of W (in case of S-HVOF) giving it a different OCP value as explained earlier. The difference in the $E_{\text {corr }}$ and OCP of this coating is surprising. However, the microstructure has a role to play in this as well. As the polarization experiments were conducted from the cathodic side where the cathodic reduction of dissolved oxygen was favored, the local $\mathrm{pH}$ would have risen which would favor the passive oxide dissolution rate. This fits well with the observation by Kelsey (Ref 38) who found that at $\mathrm{pH}$ values above 8 , the passive oxide dissolution rate increases as the $\mathrm{WO}_{3}$ films are rapidly dissolved away in highly alkaline solvents. Thus, the local chemistry at the surface of the sample was probably different during polarization experiments and the OCP measurements which perhaps resulted in different $E_{\text {corr }}$ and OCP values for S-HVOF. As the other coatings did not contain metallic $\mathrm{W}$, no such behavior was observed.

According to the Pourbaix diagram of tungsten (Ref 39), a passivating film on the tungsten can only form in a solution with a $\mathrm{pH}$ less than 4 . Several experiments with a range of $\mathrm{pH}$ from 1.2 to 5 were investigated by Bothra et al. (Ref 40). Passivation and prevention of tungsten plug corrosion were obtained at $\mathrm{pH}$ values of less than 2.2. At higher $\mathrm{pH}$ values, corrosion of tungsten still occurred. According to the Pourbaix diagram and study by Bothra et al. (Ref 40), below a pH of 4.0, there is always a thin layer of $\mathrm{WO}_{2(\mathrm{~s})}$ present on the tungsten surface. At $\mathrm{pH}$ below $\sim 2.2$, a stable phase of $\mathrm{WO}_{3(\mathrm{~s})}$ grows on the surface and this is likely to serve as a barrier and mitigates further corrosion of tungsten. In the $\mathrm{pH}$ range of 2.2-5.0, a stable phase of $\mathrm{WO}_{3}(\mathrm{~s})$ is not formed; rather, a stable polytungstate species was formed which offered no passivation. From the above discussion, it is clear that metallic tungsten plays a role in the corrosion performance of the S-HVOF, possibly to its detriment.

Apart from the influence of microstructural phases, HVOF-sprayed WC-Co coatings are also reported to show crevice corrosion (Ref 41), probably initiated at some weak splat boundaries. Once the crevice is initiated, the oxygen depletion inside the crevice ensues. The $\mathrm{pH}$ in the crevice rapidly decreases, and high-mobility chloride ions migrate into the crevice, favoring hydrolysis which further decreases the solution $\mathrm{pH}$ and hence facilitating further 


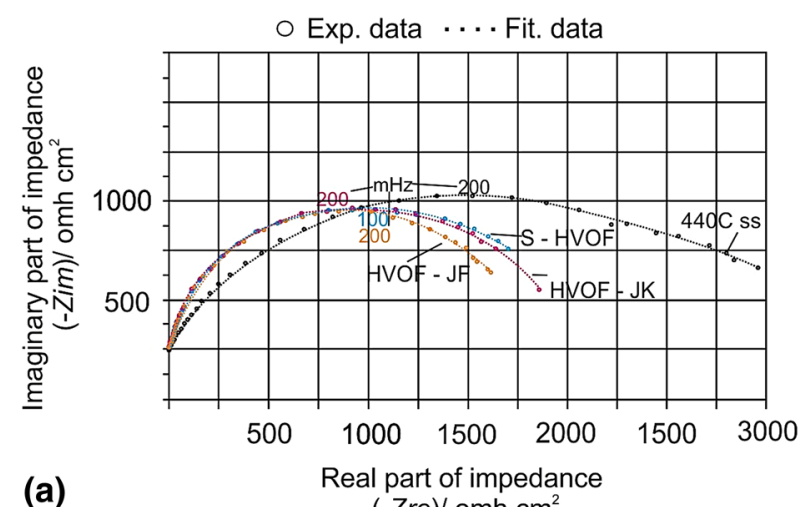

(a)

$(-Z r e) /$ omh $\mathrm{cm}^{2}$

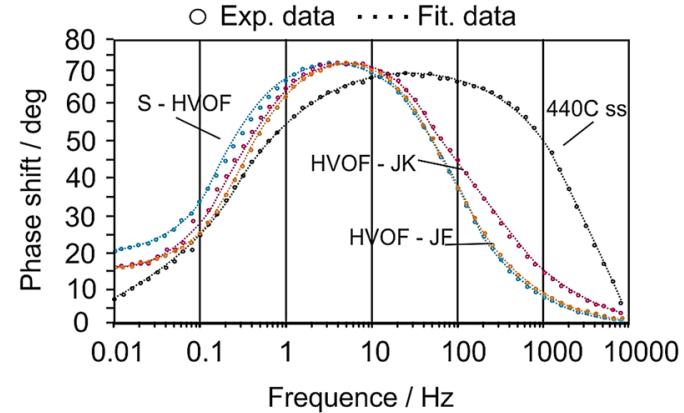

(b)

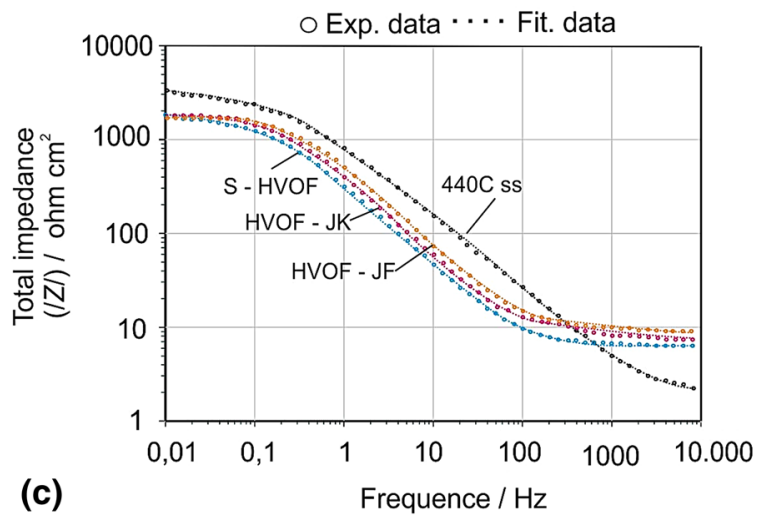

Fig. 14 (a) Nyquist plots, (b) Bode plots and (c) total impedancefrequency plots for S-HVOF-, HVOF-JK- and HVOF-JP-coated samples together with the bare substrate $(440 \mathrm{C}$ ss) obtained after

corrosion. Evidence of crevice corrosion in the current study was not conclusive.

\section{EIS Measurements}

EIS analysis can offer valuable information on the behavior of different coatings. Figure 14 shows Nyquist, Bode and total impedance-frequency diagrams for examined coated and uncoated samples obtained after a 60-min immersion in 3.5 wt. $\% \mathrm{NaCl}$ aqueous solution at $\sim 25{ }^{\circ} \mathrm{C}$.

Nyquist plots (Fig. 14a) for all specimens show an imperfect semicircle for the whole frequency range, which is characteristic of reactions where ion diffusion is relatively limited (Ref 42). Bode plots (Fig. 14b) for coated and uncoated samples show the existence of at least one, maximum two time constants due to the relative wide range of frequencies that each peak occupies (Fig. 14b). The slopes of the total impedance (/Z/)-frequency plots (Fig. 14c) show that at low frequencies $(<0.2 \mathrm{~Hz})$ they are reaching clear dc limits. The dc limits ranging from around $1800 \mathrm{Ohm} \mathrm{cm}$ (for coated samples) to $3400 \mathrm{Ohm} \times \mathrm{cm}^{2}$ (for $440 \mathrm{C}$ ss). Furthermore, the total impedance at higher frequencies (Fig. 14c) for every sample is lower, reaching values below $10 \mathrm{Ohm} \times \mathrm{cm}^{2}$, which may be because
60 min of immersion in $3.5 \mathrm{wt} . \% \mathrm{NaCl}$ aqueous solution at $\sim 25^{\circ} \mathrm{C}$. $\mathrm{Z}_{\mathrm{im}}$ and $\mathrm{Z}_{\mathrm{re}}$ are imaginary part and real part of complex impedance, respectively, whereas/Z/ is the impedance meter of complex number

diffusion of ions does not contribute to impedance at these frequencies. Finally, it must be noted that the impedances of the coated samples have relatively lower impedance values compared with the $440 \mathrm{C}$ stainless steel substrate which is in agreement with the corrosion current results.

The absence of a non-perfect semicircle at very high frequencies (Fig. 14a) can be attributed to the frequency dispersion and the absence of any continuous surface film on the specimens ("Corrosion Test Results"). Furthermore, the presence of maximum two time constants at Bode diagrams (Fig. 14b) may be related to the presence of WC grains which provide additional interfaces on the surface of the coated samples. The increase in the total impedance at low frequencies for all specimens reaching a dc limit is an indication of a complete lack of diffusion mechanism and the presence of localized corrosion (Ref 43).

\section{Equivalent Circuit Models}

For the corrosion behavior of S-HVOF-, HVOF-JK- and HVOF-JP-coated samples together with the bare stainless steel substrate (440C ss), two different equivalent electrical circuits are proposed corresponding to uncoated and coated specimens as analyzed below. 

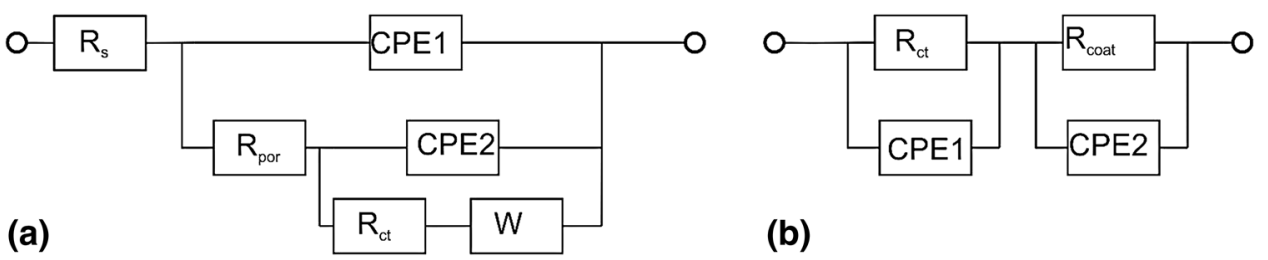

(b)

Fig. 15 Equivalent electrical circuit representing the corrosion behavior of (a) the bare substrate (440C ss) and (b) S-HVOF-, HVOF-JK- and HVOF-JP-coated samples after 60 min of immersion in $3.5 \mathrm{wt} \% \mathrm{NaCl}$ aqueous solution at $\sim 25^{\circ} \mathrm{C}$

Based on the resulted impedance curves (Fig. 14) and the previous results and discussion, two equivalent circuits (Fig. 15) were chosen in order to describe the early stages of corrosion of 440C stainless steel (Fig. 15a) and coated samples (Fig. 15b) in 3.5 wt.\% $\mathrm{NaCl}$ aqueous solution. This equivalent circuit seems to offer the most coherent physical interpretation of the results having the minimum possible electrical elements.

The adopted equivalent circuits for the $440 \mathrm{C}$ stainless steel consist of the following (Fig. 15a):

1. a resistance $R_{\mathrm{S}}$ of electrolyte solution,

2. a charged transfer resistance $R_{\mathrm{ct}}$, which characterizes the polarization of the specimens-solution interface due to the formation of an electric double layer inside any reacted area,

3. a Warburg $(W)$ resistance $Z_{\mathrm{w}}$ related to the diffusion direction of oxidants to any formed electric double layer,

4. an impedance $Z_{\mathrm{CPE} 1}$ of a constant phase element CPE1 (or CPE3) that characterizes the capacitance $C_{\mathrm{C}}$ of any oxide layer (or product's layer) on the 440C stainless steel,

5. an impedance $Z_{\mathrm{CPE} 2}$ of a constant phase element CPE2, which characterizes the capacitance contribution $C_{\mathrm{dl}}$ of any formed electric double layer on the interface between specimens and the solution inside any corrosion area,

6. a resistance $R_{\text {por }}$ that describes the solution resistance which appears within any formed pit on the surface of any specimen.

The impedance of the constant phase elements can be expressed by Eq 1 (Ref 42):

$Z_{\mathrm{CPE}}=(\mathrm{i} \omega)^{-\alpha} Q^{-1}$,

where $\omega$ is the angular frequency and $\alpha$ and $Q$ are parameters independent of the frequency. When $\alpha=1, Q$ is expressed in $\mathrm{F} \times \mathrm{cm}^{-2}$ corresponding to an ideal capacitor. When $\alpha \neq 1, Q$ is expressed in $\mathrm{s}^{\alpha} \times\left(\mathrm{ohm} \times \mathrm{cm}^{-2}\right)$ and characterizes the non-uniform charge distribution on the metal-solution interface due to surface heterogeneities. The diffusion of ionic species at the interface between the samples and the solution is common in electrochemical systems. The Warburg impedance was developed in order to model this phenomenon. One expression of Warburg resistance $Z_{\mathrm{w}}$ is given by Eq $2(\operatorname{Ref} 42)$ :

$Z_{\mathrm{W}}=A_{\mathrm{W}}(\mathrm{i} \omega)^{-0.5}$,

where $A_{\mathrm{w}}$ is the modulus of the Warburg resistance in ohm $\mathrm{cm}^{2} \mathrm{~s}^{-0.5}$.

The adopted equivalent circuits for the coated samples consist of the following (Fig. 15b):

1. a charged transfer resistance $R_{\mathrm{ct}}$, which characterizes the polarization of the specimens-solution interface due to the formation of an electric double layer on the interface between specimens and the solution inside any corrosion area. An increase in the value indicates that the increase in corrosion resistance of passive films occurs due to either film thickening or compositional modification in the corrosive environment,

2. an impedance $Z_{\mathrm{CPE} 1}$ of a constant phase element CPE1, which characterizes the capacitance contribution $C_{\mathrm{d} 1}$ of any formed electric double layer on the interface between specimens and the solution inside any corrosion area,

3. a resistance $R_{\text {coat }}$ that describes the resistance of the coating,

4. an impedance $Z_{\mathrm{CPE} 2}$ of a constant phase element CPE1 that characterizes the capacitance $\mathrm{C}_{\mathrm{coat}}$ of the coatings on the $440 \mathrm{C}$ ss substrate.

The parameters of the equivalent circuit elements in Fig. 15 after analyzing a considerable amount of fitted spectra are listed in Table 4. Besides, as shown in Fig. 14, the fit between Bode and Nyquist plots is well adjusted to the proposed equivalent electric circuit, demonstrating a good agreement between the experimental and simulated data (calculated standard error, $<10 \%$ ).

The complexity of the equivalent circuits is related to the formation process of the corrosion products and their dissolution behavior in the corresponding aggressive media. In all cases, Nyquist plots only appear in the first quadrant, exhibiting a high-frequency capacitive behavior, without any electrode or inductive response. Thus, it is difficult to predict the exact location of the capacitive oxide film formation. For example, if the oxide films are created at the substrate-coating interface, WC-Co interface or 
Table 4 Parameters of the equivalent circuits' elements (Fig. 15) representing the corrosion behavior of S-HVOF-, HVOF-JK- and HVOF-JPcoated samples together with the bare substrate $(440 \mathrm{C} \mathrm{ss})$ obtained after $60 \mathrm{~min}$ of immersion in $3.5 \mathrm{wt} \% \mathrm{NaCl}$ aqueous solution at $\sim 25{ }^{\circ} \mathrm{C}$

\begin{tabular}{|c|c|c|c|c|c|c|c|}
\hline$R_{\mathrm{s}}(\mathrm{a}), \mathrm{Ohm} \mathrm{cm} \mathrm{cm}^{-2}$ & $R_{\text {por }}(\mathrm{a}), \mathrm{Ohm} \mathrm{\textrm {cm } ^ { - 2 }}$ & $R_{\mathrm{ct}}(\mathrm{a}), \mathrm{Ohm} \mathrm{\textrm {cm } ^ { - 2 }}$ & $R_{\text {coat }}(\mathrm{a}), \mathrm{Ohm} \mathrm{cm}^{-2}$ & $\begin{array}{c}\mathrm{CPE} 1(\mathrm{a}) \\
s^{\alpha}, \mathrm{Ohm}^{-1}\end{array}$ & $\alpha_{1}(\mathrm{a})$ & $\begin{array}{c}\mathrm{CPE} 2(\mathrm{a}) \\
s^{\alpha}, \mathrm{Ohm}^{-1}\end{array}$ & $\alpha_{2}(\mathrm{a})$ \\
\hline 2.33 & 13.8 & 3237 & & 0.037 & 0.99 & 0.26 & 0.63 \\
\hline 6.20 & & 1525 & 1800 & 0.63 & 0.87 & 12.42 & 0.85 \\
\hline 6.93 & & 1345.4 & 1100 & 0.54903 & 0.92 & 5 & 0.59 \\
\hline 9.34 & & 1633.5 & 2000 & 0.39 & 0.87 & 26 & 0.99 \\
\hline
\end{tabular}

(a)Mean values

interfaces of the crystalline and amorphous/nanocrystalline constituents of the S-HVOF coating. However, from previous studies (Ref 35), it would appear that the active dissolution of the corrosion products of the WC phase and the binder phase in the medium results in greater roughness in the corrosion surfaces of the coating.

The equivalent circuits enable a better understanding of the corrosion mechanism. However, due to the complex microstructure of the HVOF coatings, particularly the S-HVOF coating where metallic tungsten and $\mathrm{W}_{2} \mathrm{C}$ exist together with a larger share of an amorphous/nanocrystalline phase, it is not trivial to analyze the data and extract useful information when such complex microstructures and pore architectures are encountered. Analysis of EIS data using equivalent circuits should be complemented by microstructural information. The mechanistic understanding is only possible when information from different techniques is collated and analyzed. This paper has adopted this approach to understand the corrosion performance of different HVOF coatings.

\section{Conclusions}

The corrosion performance of HVOF-sprayed coatings deposited by using conventional and suspension WC-Co feedstock on 440C stainless steel substrate was studied. Combining the measurements of electrochemical corrosion with the microstructural investigation before and after corrosion the following conclusions can be drawn:

1. Coatings produced by S-HVOF technique show lower corrosion resistance compared with the coatings produced by HVOF-JK and HVOF-JP techniques, most probably due to strong carbon loss during spraying leading to the presence of metallic tungsten and the presence of a higher amount of amorphous/nanocrystalline constituents compared with conventional coatings.
2. No corrosion products were found on S-HVOFsprayed corroded samples compared with JK-HVOF and JP-HVOF samples. JK-HVOF and JP-HVOF samples were found to have been significantly penetrated from the corrosion agents. No evidence of surface passivation was found on all coated samples, and it is expected that the as-sprayed coatings have a significant service life after which the substrate will begin to corrode.

3. Post corrosion test XRD analysis indicates slight reduction in the amorphous/nanocrystalline hump around $42^{\circ}$ degree indicating dissolution of amorphous/nanocrystalline material.

4. The results of the potentiodynamic polarization measurements are in general agreement with those observed in the EIS spectra.

5. Electrical models simulating the corrosion mechanism for coated samples were proposed. Further refinement of this model can include phase differences in the conventional and suspension deposited coatings.

Open Access This article is distributed under the terms of the Creative Commons Attribution 4.0 International License (http://crea tivecommons.org/licenses/by/4.0/), which permits unrestricted use, distribution, and reproduction in any medium, provided you give appropriate credit to the original author(s) and the source, provide a link to the Creative Commons license, and indicate if changes were made.

Funding Financial support of Saudi Aramco for the research project is gratefully acknowledged.

\section{References}

1. L.-M. Berger, Coatings by Thermal Spray, in Comprehensive Hard Materials, Volume 1, Hardmetals, V. Sarin, D. Mari, L. Llanes, and C. Nebel, Ed., Elsevier, Amsterdam, 2014, p 479-514

2. V. Stoica, R. Ahmed, T. Itsukaichi, and S. Tobe, Sliding Wear Evaluation of HIPed Thermal Spray Cermet Coatings, Wear, 2004, 257(11), p 1103-1124 
3. S. Stewart, R. Ahmed, and T. Itsukaichi, Rolling Contact Fatigue of Post-treated WC-NiCrBSi Thermal Spray Coatings, Surf. Coat. Technol., 2005, 190(2-3), p 171-189

4. R. Ahmed and M. Hadfield, Mechanisms of Fatigue Failure in Thermal Spray Coatings, J. Therm. Spray Technol., 2002, 11(3), p 333-349

5. S. Houdková, F. Zahálka, M. Kašparová, and L.-M. Berger, Comparative Study of Thermally Sprayed Coatings under Different Types of Wear Conditions for Hard Chromium Replacement, Tribol. Lett., 2011, 43, p 139-154

6. C. Monticelli, A. Frignani, and F. Zucchi, Investigation on the Corrosion Process of Carbon Steel Coated by HVOF WC/Co Cermets in Neutral Solution, Corros. Sci., 2004, 46, p 1225-1237

7. P.H. Shipway, D.G. McCartney, and T. Sudaprasert, Sliding Wear Behaviour of Conventional and Nanostructured HVOF Sprayed WC-Co Coatings, Wear, 2005, 259, p 820-827

8. Q. Yang, T. Senda, and A. Ohmori, Effect of Carbide Grain Size on Microstructure and Sliding Wear Behavior of HVOF-Sprayed WC-12\% Co Coatings, Wear, 2003, 254, p 23-34

9. V. Rajinikanth and K. Venkateswarlu, An Investigation of Sliding Wear Behavior of WC-Co Coating, Tribol. Int., 2011, 44(12), p 1711-1719

10. R.J.K. Wood, Tribology of Thermal Sprayed WC-Co Coatings, Int. J. Refract. Met. Hard Mater., 2010, 28(1), p 82-94

11. V. Souza and A. Neville, Mechanisms and Kinetics of WC-Co-Cr High Velocity Oxy-Fuel Thermal Spray Coating Degradation in Corrosive Environments, J. Therm. Spray Technol., 2006, 15(1), p 106-117

12. V. Souza and A. Neville, Aspects of Microstructure on the Synergy and Overall Material Loss of Thermal Spray Coatings in Erosion-Corrosion Environments, Wear, 2007, 263(1-6), p 339346

13. L.-M. Berger, Binary WC- and $\mathrm{Cr}_{3} \mathrm{C}_{2}$-Containing Hardmetal Compositions for Thermally Sprayed Coatings, IOP Conf. Ser. Mater. Sci. Eng., 2016, 118, p 012010

14. M. Magnani, P.H. Suegama, A.A. Cândido Recco, J.M. Guilemany, C.S. Fugivara, and A.V. Benedetti, WC-CoCr Coatings Sprayed by High Velocity Oxygen-Fuel (HVOF) Flame on AA7050 Aluminum Alloy: Electrochemical Behavior in 3.5\% $\mathrm{NaCl}$ Solution, Mater. Res., 2007, 10(4), p 377-385

15. J.A. Picas, E. Rupérez, M. Punset, and A. Forn, Influence of HVOF Spraying Parameters on the Corrosion Resistance of WCCoCr Coatings in Strong Acidic Environment, Surf. Coat. Technol., 2013, 225, p 47-57

16. M.S. El-Basiouny, S.A. Hassan, and M.M. Hefny, On the Electrochemical Behaviour of Tungsten: The Formation and Dissolution of Tungsten Oxide in Sulphuric Acid Solutions, Corros. Sci., 1980, 20, p 909-917

17. P. Fauchais, G. Montavon, R.S. Lima, and B.R. Marple, Engineering a New Class of Thermal Spray Nano-Based Microstructures from Agglomerated Nanostructured Particles, Suspension and Solutions: An Invited Review, J. Phys. D Appl. Phys., 2011, 44, art no. 093001

18. J. Oberste Berghaus, B. Marple, and C. Moreau, Suspension Plasma Spraying of Nanostructured WC-12Co Coatings, $J$. Therm. Spray Technol., 2006, 15(4), p 676-681

19. V. Chawla, B.S. Sidhu, D. Puri, and S. Prakash, State of Art: Plasma Sprayed Nanostructured Coatings: A Review, Mater. Forum, 2008, 32, p 137-143

20. L.-M. Berger, F.-L. Toma, and A. Potthoff, Thermal Spraying with Suspensions-An Economic Spray Process, Therm. Spray Bull., 2013, 6(2), p 98-101

21. F.-L. Toma, L.-M. Berger, S. Langner, and T. Naumann, Suspension Spraying-The Potential of a New Spray Technology, Therm. Spray Bull., 2010, 3(1), p 24-29
22. O. Ali, R. Ahmed, N.H. Faisal, N.M. Al-Anazi, L.-M. Berger, A. Kaiser, F.-L. Toma, E.K. Polychroniadis, M. Sall, Y.O. Elakwah, and M.F.A. Goosen, Influence of Post-treatment on the Microstructural and Tribomechanical Properties of Suspension Thermally Sprayed WC-12 wt.\% Co Nanocomposite Coatings, Tribol. Lett., 2017, 65, paper 33

23. R. Ahmed, N.H. Faisal, N.M. Al-Anazi, S. Al-Mutairi, F.-L. Toma, L.-M. Berger, A. Potthoff, E.K. Polychroniadis, M. Sall, D. Chaliampalias, and M.F.A. Goosen, Structure Property Relationship of Suspension Thermally Sprayed WC-Co Nanocomposite Coatings, J. Therm. Spray Technol., 2014, 24(3), p 357377

24. R. Ahmed, O. Ali, N.H. Faisal, N.M. Al-Anazi, S. Al-Mutairi, F.L. Toma, L.-M. Berger, A. Potthoff, and M.F.A. Goosen, Sliding Wear Investigation of Suspension Sprayed WC-Co Nanocomposite Coatings, Wear, 2015, 322-323, p 133-150

25. S. Stewart and R. Ahmed, Contact Fatigue Failure Modes in Hot Isostatically Pressed WC-12\%Co Coatings, Surf. Coat. Technol., 2003, 172, p 204-216

26. S. Osawa, T. Itsukaichi, and R. Ahmed, Influence of Substrate Properties on the Impact Resistance WC Cermet Coatings, $J$. Therm. Spray Technol., 2005, 14(4), p 495-501

27. L.-M. Berger, K. Lipp, J. Spatzier, and J. Bretschneider, Dependence of the Rolling Contact Fatigue of HVOF-Sprayed WC-17\%Co Hardmetal Coatings on Substrate Hardness, Wear, 2011, 271(9-10), p 2080-2088

28. A.K. Basak, J.-P. Celis, P. Ponthiaux, F. Wenger, M. Vardavoulias, and P. Matteazzi, Effect of Nanostructuring and $\mathrm{Al}$ Alloying on Corrosion Behaviour of Thermal Sprayed WC-Co Coatings, Mater. Sci. Eng. A, 2012, 558, p 377-385

29. M.M. Verdian, K. Raeissi, and M. Salehi, Corrosion Performance of HVOF and APS Thermally Sprayed NiTi Intermetallic Coatings in 3.5\% NaCl Solution, Corros. Sci., 2010, 52, p 1052-1059

30. A. Lekatou, D. Zois, A.E. Karantzalis, and D. Grimanelis, Electrochemical Behaviour of Cermet Coatings with a Bond Coat on A17075: Pseudopassivity, Localized Corrosion and Galvanic Effect Considerations in a Saline Environment, Corros. Sci., 2010, 52, p 2616-2635

31. A.M. Human and H.E. Exner, Electrochemical Behaviour of Tungsten-Carbide Hard Metals, Mater. Sci. Eng. A, 1996, 209, p $180-191$

32. K.H. Gayer and A.B. Garrett, The Solubility of Cobalt Hydroxide, $\mathrm{Co}(\mathrm{OH})_{2}$, in Solutions of Hydrochloric Acid and Sodium Hydroxide at $25{ }^{\circ} \mathrm{C}, \mathrm{J}$. Am. Chem. Soc., 1950, 72(9), p 3921-3923

33. A.M. Human, I.T. Northrop, S.B. Luyckx, and M.N. James, A Comparison Between Cemented Carbides Containing Cobalt- and Nickel-Based Binders, J. Hard Mater., 1991, 2(3-4), p 245-256

34. S. Hochstrasser-Kurz, Y. Mueller, C. Latkoczy, S. Virtanen, and P. Schmutz, Analytical Characterization of the Corrosion Mechanisms of WC-Co by Electrochemical Methods and Inductively Coupled Plasma Mass Spectroscopy, Corros. Sci., 2007, 49, p 2002-2020

35. L. Zhang, Y. Chen, Q.-L. Wan, T. Liu, J. Zhu, and W. Tian, Electrochemical Corrosion Behaviors of Straight WC-Co Alloys: Exclusive Variation in Grain Sizes and Aggressive Media, Int. J. Refract. Met. Hard Mater., 2016, 57, p 70-77

36. D.S. Konadu, J. Merwe, J.H. Potgieter, S. Potgieter-Vermaak, and C.N. Machio, The Corrosion Behaviour of WC-VC-Co Hardmetals in Acidic Media, Corros. Sci., 2010, 52, p 3118-3125

37. S. Chen, W. Xiong, Z. Yao, G. Zhang, X. Chen, B. Huang et al., Corrosion Behavior of $\mathrm{Ti}(\mathrm{C}, \mathrm{N})-\mathrm{Ni} / \mathrm{Cr}$ Cermets in $\mathrm{H}_{2} \mathrm{SO}_{4}$ Solution, Int. J. Refract. Met. Hard Mater., 2014, 47, p 139-144

38. G.S. Kelsey, The Anodic Oxidation of Tungsten in Aqueous Base, J. Electrochem. Soc., 1997, 124, p 814-819

39. E.A. Kneer, C. Raghunath, S. Raghavan, and J.S. Jeon, Electrochemistry of Chemical Vapor Deposited Tungsten Films with 
Relevance to Chemical Mechanical Polishing, J. Electrochem. Soc., 1996, 143(12), p 4095-4100

40. S. Bothra, H. Sur, and V. Liang, A New Failure Mechanism by Corrosion of Tungsten in a Tungsten Plug Process, Microelectron. Reliab., 1999, 39(1), p 59-68

41. G. Bolelli, R. Giovanardi, L. Lusvarghi, and T. Manfredini, Corrosion Resistance of HVOF-Sprayed Coatings for Hard Chrome Replacement, Corros. Sci., 2006, 48(11), p 3375-3397
42. C.A. Vogiatzis, D.T. Kountouras, and S.M. Skolianos, Corrosion Behaviour of 304 Stainless Steel in Simulated Oilfield Produced Water, J. Corros. Eng. Sci. Technol., 2016, 51(1), p 51-59

43. G.-L. Song and M. Liu, Corrosion and Electrochemical Evaluation of Al-Si-Cu Aluminum Alloy in Ethanol Solutions, Corros. Sci., 2013, 72, p 73-81 